\title{
LANDSCAPE ECOLOGY AND THE GENERAL THEORY OF RESOURCES: COMPARING TWO PARADIGMS
}

\author{
ALMO FARINA \\ Department of Basic Sciences and Fundamentals, Urbino University, Italy, \\ e-mail: almo.farina@uniurb.it
}

Received: $3^{\text {rd }}$ May 2011, Accepted: $20^{\text {th }}$ June 2011

\begin{abstract}
This paper is an attempt to connect the General Theory of Resources (GTR) with the principles that guide the Landscape Ecology Principles (LEP). The recent GTR is based on the assumption that resources are the common requirement for individual species, populations, communities and ecosystems. We therefore describe the main characteristics of resources, while the biosemiotic mechanisms with which to track them are also discussed.

Moreover, and with a view to their reinterpretation, we have confronted the issues of patch shape, heterogeneity, corridors, ecotones and fragmentation with these GTR principles. According to the thesis presented in this paper, resources can be tracked using the specific spatial configuration carrier of meaning (the eco-field), while the major features of landscapes, such as size, shape and the distribution of patches, are used by organisms (animals) as a semiotic cue with which to identify eco-fields and associated resources.
\end{abstract}

\section{INTRODUCTION}

The General Theory of Resources (GTR) has recently been presented to the fields of ecology and biosemiotics (Farina 2010, pp. 115, Farina 2011). This theory uses resources as the general criterion with which to investigate and interpret the ecological complexity of the real world, while the domain of biosemiotics is adopted as the central mechanism utilized by (animal) organisms to intercept their resources.

Resources are the common factor necessary to the maintenance of individuals, populations, communities and ecosystems across a wide range of functional scales (sensu Allen \& Hoekstra 1992). They are also objects that require a spatial configuration to be allocated, tracked and utilized by organisms. Space immediately recalls the concept of the landscape and the spatial arrangement of objects. For this reason, the resource criterion and the landscape approach seem to be two elements upon which it may be possible to identify a conceptual convergence with which to address the issue of environmental complexity, as highlighted by Farina (2008) and Farina \& Napoletano (2010), who have recognized the landscape as a biosemiotic interface between organisms and resources.

The landscape has been described and modelled by adopting both geographical and ecological approaches (Naveh \& Lieberman 1984, Forman \& Godron 1986, Turner 1989, Farina 2006), thus creating a set of principles that are well accepted in the ecological realm 
(e.g. Wu \& Hobbs 2002). In this paper, we will use the LEP (Landscape Ecology Principles) acronym to generically indicate this group of principles, some of which will later be described in detail.

Resources are regarded as objects that exist in a spatial/temporal domain, and the landscape, which is traditionally defined as an organized, informative and meaningful space, seems to be the natural recipient when it comes to supporting/maintaining the resources available to organisms, including for their scalar aggregation.

It is our aim to discuss the GTR in relation to landscape issues in terms of patterns and processes which can cross both the resource approach and the landscape.

We strongly believe that the biosemiotics' process may be the best candidate for achieving a GTR and LEP epistemological closure. Accordingly, a triadic connection, Resources-Biosemiosis-Landscape, is a natural and necessary step, and will be proposed, extensively presented and discussed in this paper (Fig. 1).

The conceptual integration between the GTR and the LEP is a new opportunity to both reinforce ecological theory (Tilman 1985, Scheiner et al. 1993, Scheiner \& Willig 2007) and open up a "grand vista" under the anthropocene challenges (sensu Crutzen 2002, Anonymous 2003, Zalasiewicz et al. 2008) that humanity has to face at the present time in terms of biodiversity conservation, human well-being, social equity (MEA 2005a,b) and sustainability (Sayer \& Campbell 2004).

Fig. 1: A functional relationship between the landscape and resources is obtained by the individual-based interpretation adopting biosemiotic mechanisms.

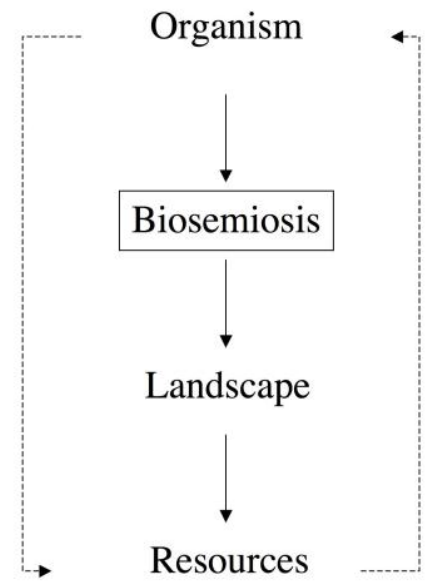




\section{Definition and characteristics of resources}

The term "resource" is widely used in ecology, economics and social sciences, and is often associated with the concepts "natural capital" and "ecosystem services" (Costanza et al. 1997). The word "resource" literally means "re-surgere", from the Latin "(surgere) spring (re) again", while the Oxford English dictionary defines resources as: "a stock or supply of materials or assets that can be drawn on in order to function effectively."

It is possible to distinguish different categories of resources based on the approach chosen. This can be:

According to consistency: material (e.g. proteins); and immaterial (e.g. energy, information, meaning and culture);

According to origin: abiotic and biotic (biotic resources may be further distinguished into those that are alive and those that are not);

According to their abundance as measured by the users thereof: limited (such as food) and unlimited (such as light);

According to the semiotic mechanisms utilized to track them: indexical, iconical and symbolic;

According to the level of complexity: simple (like water) or complex (like cultural identity or biodiversity);

According to origin: allochthonous and autochthonous; and

According to the level of importance when it comes to sustaining individual autopoiesis (sensu Maturana \& Varela 1980): necessary, optional and unnecessary.

\section{Properties of resources}

Resources, although extremely variable in terms of their origin, consistency and dynamics, share some common properties. Accordingly, they:

Rise again after depletion;

Have regular characteristics that facilitate their identification;

Are unevenly distributed in space and time;

Are hidden to escape the consumers thereof (predators);

Are coupled with a specific eco-field;

Are pulsing in space and time; and

Disappear together into the specific eco-field when neglected by their users.

Resources that are contemporarily shared between intra- or inter-specific individuals create competition processes. However, even available resources cannot be used to their full extent, and a mechanism of trade-offs regulates their relationships and utilization.

\section{The mechanisms of resource tracking}

Until recently, semiosis was regarded as an argument which was exclusive to linguistics and not an issue for biologists or ecologists. Yet today, as a novel field of active research, biosemiotics, has successfully introduced semiosis into the biological sciences (e.g. Barbieri 2008, Favareau 2010). Encouraged by this new perspective, it is possible to postulate a semiotic mechanism as the basis of the connection between organisms and resources. To achieve this semiotic closure, it is necessary for organisms to absolutely recognize resources as such by using a "semethic relationship". 
According to Hoffmeyer (2008), a semethic (from semion (sign) + ethos (habit)) interaction represents a 'personal' reciprocal knowledge that is established between organisms and resources along a co-evolutionary process. This is one of the most important elements introduced into the GTR and is, at the same time, the strength of the theory.

In fact, the matter, energy and information which represent the basic components of every resource require a "meaning" process to be definitively identified. The process of signification (identification) is necessary for either material resources like food, or for "energetic" resources, such as the patterned energy associated with the acoustic activity of animals.

The elements that comprise the mechanisms by which resources are intercepted are the result of a perceptive process that is contemporarily associated with an interpretative process. This represents the necessary connection between the "internal world" of an individual organism and the "external world". This external world is interpreted subjectively, and is coincident with the concept of "Umwelt", as argued a century ago (Jacob von Uexküll, 1982).

The identification of resources requires further steps of signification beyond "simple" perception. The searching process with which to intercept resources offers an organism the option to select a part of the available space. This means that instead of looking for a resource everywhere in their surroundings, organisms have the opportunity to select a specific part of the available space and search for a spatial configuration carrier of meaning all around them. We have described such a spatial configuration as an eco-field (Farina \& Belgrano 2004, 2006). The eco-field enables the connection between the organism and resources to be made by using a specific genetically or culturally fixed mechanism of research and identification. For every resource, a specific eco-field should exist.

Resources are tracked by adopting a double mechanism of signification. The first step consists of an investigation of the resource-specific eco-field, while the second requires the identification of the resource inside the identified eco-field. The semiotic process involved reduces the expenditure of energy invested into the process of resource tracking, thereby producing evolutionary benefits for the particular species.

To complete the description of such a semiotic mechanism, it is necessary to hypothesize that the entire process is originated by the appearance inside an organism of a need for a specific resource. Such a need should lead to the emergence of a cognitive template - "a search image" - that is able to recognize a specific eco-field. The identification of the ecofield then enables the requested resource to be found (Fig. 2). Each resource is strictly connected to a specific eco-field, thus representing a central axiom which creates and supports an epistemological bridge between the GTR and the LEP, as illustrated later in this paper. 
Fig. 2: Entering into the details of the biosemiotic mechanisms means that need, as the starting process in resource tracking, must be considered. Needs require specific ecofields to have access to related resources.

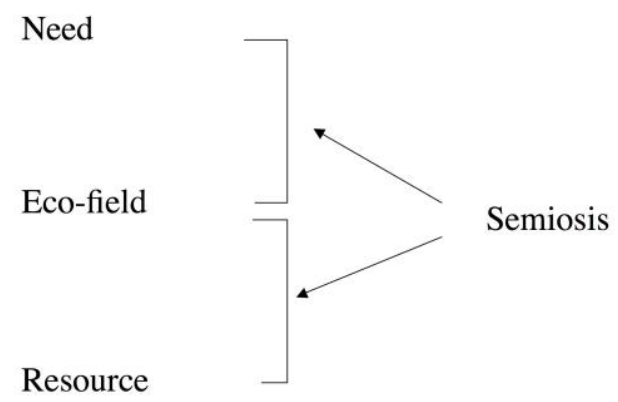

\section{The peculiar properties of the eco-field: towards a new definition of habitat}

The eco-field is a spatial configuration of objects that produce a specific meaning in a species, and can also be defined as the container for the necessary information required to find a resource. Consequently, a specific resource that is needed by an individual species is associated with each eco-field, for example: a food and foraging eco-field; a safety and refuge eco-field; an energy recovery and roosting eco-field; a brood and breeding eco-field; and a territory and acoustic eco-field.

The theory of the eco-field assumes that the same object can be utilized by an individual to identify different spatial configurations. In the example set out in Fig. 3, the distribution of a nesting (a) and a foraging eco-field (b) obtained from the same family of objects (in this case trees) is represented. The partial overlap of the different eco-fields creates the living space for an individual species.

All species live in a "perceived" and a "personal" world, and because of this the different interpretations of the external world enables more individuals and different species to live in the same spatial context while extracting the different resources required in a noncompetitive manner.

A species must have access to all necessary and optional resources to stay alive and avoid extinction, and this requirement must be achieved inside a space delimited by energetic constraints.

The totality of the eco-fields that a species requires to find resources represents a living space that is conceptually coincident with the habitat (Fig. 4). In this way, the habitat becomes the space in which a species finds all necessary and optional resources.

According to this definition, it is possible to revisit some of the milestones of ecological theory. For instance, the source-sink model (Pulliam 1988, 1996) can be re-interpreted to 
estimate the completeness of a resource-set that is necessary if an individual is to achieve a status of well-being.

In a source population, the demographic balance is positive, while a sink population is able to exist thanks to the flux of immigrants from elsewhere, because the intrinsic demographic balance is negative. This model can thus be reinterpreted by adopting the GTR, in which it is now stated as follows: when the necessary and optional resources are contemporarily present and abundant, the area can sustain source-type populations, but when resources are scarce, the area may only support sink populations.

Fig. 3: Roosting eco-field (B) and foraging eco-field (C) generated inside a common tree matrix (A) as an example of the spatial overlapping of different eco-fields.

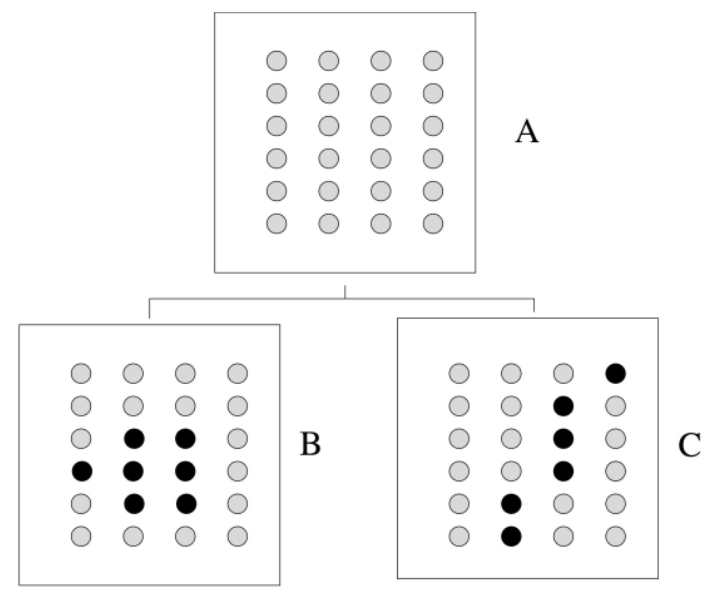

Fig. 4: In this conceptual scheme, the habitat is the result of the spatial overlap of all of the eco-fields necessary to track individual resources $(a, b \ldots$ e.. $)$.

Resources $\quad$ Eco-fields Habitat
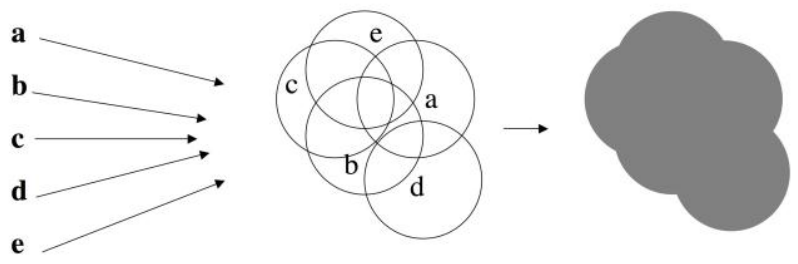

Moreover, according to the GTR (Farina 2011), the existence of a spatial configuration carrier of meaning (eco-field) does not automatically guarantee the abundance of a resource, but simply indicates the context in which a specific resource may be found. The 
abundance or scarcity of resources is independent of the eco-field configuration, and in cases in which resources are scarce, such areas can be regarded as ecological traps (see Gilroy \& Sutherland 2007 for a revision).

In fact, according to our model, when an eco-field is selected, the presence or absence of resources is assessed only in a second temporal step, while the success or failure of a settlement depends mainly on the heterogeneous distribution of resources and not on the capacity of an organism to find the eco-field associated with the best stock of resources. This is because this linkage is not established.

The eco-field theory operates either for material resources like food, or for immaterial resources like safety or acoustic configuration. Our point is that each eco-field has a geographical space in common, in which there are heterogeneously distributed material objects like rock outcrops, soil, plants and animals, but also structured energy like sounds and cultural cornerstones, expressed as "mental maps" (e.g. Gould \& White 1986).

When the objects that comprise the eco-fields are involuntarily removed by human activity or a high energy event like a tornado or tsunami, resources can no longer be utilized and are definitively lost. The opposite is also true: when resources are destroyed, contaminated or neglected (such as when land abandonment affects rural areas), the ecofields can remain apparently intact for a long time, producing a misleading message.

\section{Some relevant characteristics of the landscape}

From a geographical and ecological point of view, the landscape may be defined as a heterogeneous space in which separate patches are embedded in a matrix of a dominant land cover (Forman \& Godron 1986). It is quite clear that the landscape can be a large area and that the larger an area is, the greater the environmental heterogeneity and diversity that can be found there (MacArthur 1972). This heterogeneity means a mix of species and, consequently, a potentially high level of diversity. But heterogeneity also means that an individual species is present in a location with a population which varies in size according to this level of heterogeneity. Generally, the greater the heterogeneity the smaller the size of the population observed. This means that the set of resources available for a species is progressively restricted spatially as heterogeneity rises.

When the environment is manipulated (especially by man, but also by several other species, leading to environmental modifications (see e.g. Odling-Smee 2003, Dostal et al. 2005, Vlasakova et al. 2009), such manipulation ultimately has consequences for the distribution and abundance of resources, and the shape of the landscape thus becomes an important indicator of organism distribution. In this way, the connection between the GTR and the LEP becomes evident. In order to illustrate this idea in the best possible way, we have included some specific but limited examples:

\section{Patch shape and GTR}

The over simplification of the natural shape of vegetation cover caused by human intrusion reduces the complex and involuntary fractal design of nature and this has negative effects on many species of organisms (Krummel et al. 1987). What types of resources are connected to the complex margins created by natural processes continues to be a disputed issue. In fact, according to the GTR, the eco-fields that are in the convoluted margins could be eco-fields connected to safety (Farina \& Napoletano 2010), or, alternatively, the complex geometry of margins could favour additional resources, and the related eco-field could act as a consequence thereof (Fig. 6).

It is intuitive to state that organisms have both evolved while coping with environmental complexity and incorporated into their genetic system all of the interpretative mechanisms 
that guide them towards the more favourable options. When human use of the land suddenly produces an oversimplification of the system, most organisms have no cognitive template with which to recognize such configurations, which become meaningless and, as a consequence, interfere with interactions with resources.

Fig. 6: The convoluted shape of margins probably represents the safety eco-field (antipredator resource) for some wildlife, while the linear border could be meaningless patterns.

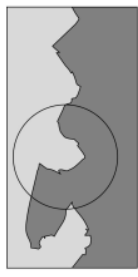

A

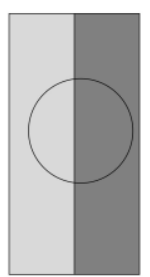

B

\section{Heterogeneity and GTR}

Spatial heterogeneity is an inherent characteristic of the landscape. This pattern has been extensively studied by ecologists, who have recognized at least three types thereof: spatial, temporal and functional (e.g. Pickett \& White 1985, Turner 1987, Kolasa \& Pickett 1991). For some species, heterogeneity has positive effects, and this means that this pattern creates positive conditions in terms of resource distribution. Yet some species can be negatively affected by land heterogeneity, especially when the heterogeneity is the product of human activity. The link between land heterogeneity and the GTR is neither simple nor immediate, because this largely depends on several conditions such as: the relationship between heterogeneity and fragmentation; heterogeneity and ecotone extension; and heterogeneity and patch shape and size, which are all intimately connected with each other.

\section{Corridors and GTR}

Corridors are defined as a strip of vegetation enabling the movement of wildlife or other organisms between two areas (e.g. Hilty et al. 2006). They are invoked by planners and landscape designers as a way to mitigate landscape isolation, and are often considered to be the panacea when it comes to mitigating habitat reduction (Simberloff et al. 1992, Collinge 2000, Nicholls et al. 2001).

A corridor is a piece of land used by individual species to complete their resource tracking. It is also the space that must be covered before the next eco-field that is necessary to completing this resource tracking process is found (Fig. 5). A "green" corridor, for example, is a piece of a favourable strip of land that is surrounded by hostile conditions. In such a case, the safety or the explorative eco-field could justify the use of such a corridor, in which the conditions for a stable population are inadequate, due to the absence of other necessary or optional resources and connected eco-fields. The boundary between a habitat 
and a true corridor is not well designed, and the word "corridor" is often used either to define a "path" or to indicate a habitat with an incomplete set of resources.

\section{Fig. 5: When some eco-fields are disjuncted, resources require corridors to be tracked.}
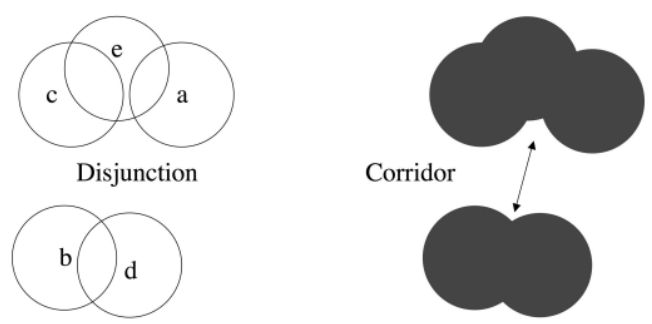

\section{Ecotones and GTR}

Ecotones are central in landscape ecology (Holland et al. 1991, Hansen \& Di Castri 1992). Defined as tension zones between two different ecological systems, ecotones have been at the centre of ecological research during the past 30 years (Farina 2010), and the high variety of environmental conditions therein favour the presence of many species.

Some species live in ecotones, and this means that they are able to find all of the resources they require. In these circumstances, ecotones may be regarded as true habitats. In other cases, they function like a barrier, meaning that for other species, either ecotones are areas in which there are not enough resources, or these species do not have the capacity to recognize eco-fields when two different, structured environmental assets come into contact.

\section{Fragmentation and GTR}

Fragmentation is one of the most common processes, and it occurs particularly due to the effect of land cover changes and disturbance (Wiens 1994). The most common example is the primary fragmentation of forests, which are replaced with croplands, but also relevant is the secondary fragmentation of the rural landscape by urban sprawls and infrastructures like railways and motorways.

Fragmentation reduces the number of favourable areas available to species and creates gaps and isolation between habitat patches (Saunders et al. 1991). Isolated patches may function as being connected when a species has the ability to move from one to another while searching for resources, without losing too much energy. However, when energetic expenditure overcomes energetic gain, an individual species enters into a status of ill-being. At the start of fragmentation, when patches are large enough, resources are located in the same area, but when the patches are reduced in size and not all of the resources required can be found, species are obliged to move outside the particular patch. At that moment, there is a disjunction of habitat and the cost of such displacement has to be considered. 


\section{DISCUSSION AND CONCLUSIONS}

The current LEP recognize in patches the units that comprise the landscape, which is defined as a geographical, heterogeneous medium. However, there is evidence that all species perceive such configurations differently, as highlighted by Wiens \& Milne (1989) in their seminal paper on the beetle landscape. Resources that are to be intercepted and recognized by organisms require specific eco-fields (spatial configuration of objects' carrier of meaning), which are regarded in our hypothesis as the elementary unit of the (cognitive) landscape. Eco-fields are the functional patches of an individual-based landscape. The totality of the species-specific eco-fields becomes the landscape for a species, and this perceived entity is coincident with the habitat for that species.

The eco-field represents the perceived element that is necessary to locate a specific resource, while landscape patterns and processes, like heterogeneity, fragmentation, diversity and shape complexity, are finally and strictly connected with resources. This grand synthesis enables the landscape, which is often reduced to a simple, visual and aesthetic component of the environment (Barrett et al. 2009), to be reconciled as a necessary biosemiotic interface with which to intercept resources with the functional perspective of ecosystems.

Moreover, when the landscape is regarded as a biosemiotic interface between organisms and resources, many of the hypotheses used to explain the patterns observed find a more logical and reasonable explanation. The shape of the objects and their spatial distribution, which have empirically been recognized as important proxies for organisms on the basis of the Landscape Ecology Principles, also find a more convincing explanation when the GTR is adopted. Biosemiotics enter into this new scenario as the mechanism adopted by a species to "interpret" the external world. Shape, size and spatial configuration become the elements of an organic code (sensu Barbieri 2003) with which to interpret the complexity of the surroundings and discover resources, which is a necessary step if an organism is to survive.

\section{REFERENCES}

Allen, T.F.H., Hoekstra, T.W. (1992). Toward a unified ecology. Columbia University Press, New York.

Anonymous (2003). Welcome to the anthropocene. Nature 424:709.

Barbieri, M. (2003). The organic codes. An introduction to semantic biology. Cambridge University Press, Cambridge.

Barbieri, M. (2008). What is Biosemiotics. Biosemiotics 1:1-3.

Barrett, T. I., Farina, A. \& Barrett, G. W. (2009). Aesthetic landscapes: an emergent component in sustaining societies. Landscape Ecology, DOI:10.1007/s10980-009-9354-8.

Collinge, S.K. (2000). Effects of grassland fragmentation on insect species loss, colonization, and movement patterns. Ecology 81: 2211-2226.

Costanza, R., d'Arge, R., de Groot, R., Farber, S., Grasso, M., Hannon, B., Limburg, K., Naeem, S., O’Neill, R.V., Paruelo, J., Raskin, R.G., Sutton, P. \& van der Belt, M. (1997). The value of the world's ecosystem services and natural capital. Nature 387:253-260.

Crutzen, P. J. (2002). Geology of mankind. Nature 415: 23. 
Dostal, P., Breznova, M., Kozlickova, V., Herben, T. \& Kovar, P. (2005). Ant-induced soil modification and its effect on plant below-ground biomass. Pedobiologia 49: 127-137.

Farina, A. (2006). Principles and methods in landscape ecology. Towards a science of landscape. Springer, Dordrecht.

Farina, A. (2008). The landscape as a semiotic interface between organisms and resources. Biosemiotics 1(1): 75-83.

Farina, A. (2010). Ecology, Cognition and Landscape. Linking natural and social systems. Springer, Dordrecht.

Farina, A. (2011). A biosemiotic perspective for a Resource Criterion: Toward a General Theory of Resources. Biosemiotics DOI: 10.1007/s12304-011-9119-z

Farina, A., Belgrano, A. (2004). The eco-field: A new paradigm for landscape ecology. Ecological Research 19: 107-110.

Farina, A., Belgrano, A. (2006). The eco-field hypothesis: Toward a cognitive landscape. Landscape Ecology 21: 5-17.

Farina, A., Napoletano B. (2010). Rethinking the Landscape: New Theoretical Perspectives for a Powerful Agency. Biosemiotics 3:177-187. DOI 10.1007/s12304-010-9086-9

Favareau, D. (2010). Essential reading in Biosemiotics. Springer, New York.

Forman, R.T.T., Godron, M. (1986). Landscape ecology. Wiley \& Sons, New York.

Gilroy, J.J., Sutherland, W.J. (2007). Beyond ecological traps: perceptual errors and undervalued resources. Trends in Ecology and Evolution 22 (7): 351-356.

Gould, P., White, R. (1986). Mental maps. Allen \& Unwin, London.

Hansen, A.J., di Castri, F. (1992). Landscape boundaries. Consequences for biotic diversity and ecological flows. Springer-Verlag, New York.

Hilty, J.A., Lidicker, W. Jr. \& Merenlender, A.M. (2006). Corridor ecology. The science and practice of linking landscapes for biodiversity conservation. Island Press, Washington DC.

Hoffmayer, J. (2008). Biosemiotics. An Examination into the Signs of Life and the Life of Signs. Scranton University Press, Scranton PA.

Holland, M.M., Risser, P.G. \& Naiman, R.J. (1991). Ecotones. The role of landscape boundaries in the management and restoration of changing environments. Chapman \& Hall, London, UK.

Kolasa, J., Pickett, S.T.A. (1991). Ecological heterogeneity. Springer-Verlag, New York.

Krummel, J.R., Gardner, R.H., Sugihara, G., O’Neill, R.V. \& Coleman, P.R. (1987). Landscape patterns in a disturbed environment. Oikos 48: 321-324.

Macarthur, R.H. (1972). Geographical ecology. Pattern in the distribution of species. Princeton Univesity Press, Princeton, NJ.

Maturana,, H.R., Varela, J. F. (1980). Autopoiesis and Cognition. The realization of the living. Rediel Publishing Company, Dordrecht, Holland.

MEA (Millennium Ecosystem Assessment) (2005a). Ecosystems and human well-being: Synthesis. Island Press, Washington.

MEA (Millennium Ecosystem Assessment) (2005b). Ecosystems and human well-being: Biodiversity synthesis. Island Press, Washington. 
Naveh, Z., Lieberman A.S. (1984). Landscape ecology - Theory and application. SpringerVerlag, New York.

Nicholls, C.I., Parrella, M. \& Altieri, M.A. (2001). The effects of a vegetational corridor on the abundance and dispersal of insect biodiversity within a northern California organic vineyard. Landscape Ecology 16: 133-146.

Pickett, S.T.A., White, P.S. (1985). The ecology of natural disturbance and patch dynamics. Academic Press, New York.

Odling-Smee, F. J. (2003). Niche Construction. Princeton University Press, Princeton NJ.

Pulliam, H.R. (1988). Source-sinks, and population regulation. American Naturalist 132: 652-661.

Pulliam, H.R. (1996). Sources and sinks: empirical evidence and population conservation. In: Rhodes, O.E., Chesser, R.K., Smith, M.H. (Eds.), Population dynamics in ecological space and time. pp. 45-69. The University of Chicago Press, Chicago.

Saunders, D.A., Hobbs, R.J. \& Margules, C.R. (1991). Biological consequences of ecosystem fragmentation: A review. Conservation Biology 9: 1072-1084.

Sayer, J., Campbell, B. (2004). The science of sustainable development. Cambridge University Press, Cambridge, UK.

Scheiner, S.M., Hudson, A.J. \& VanderMeulen, M.A. (1993). An epistemology for ecology. Bulletin Ecological Society of America 74(1): 17-21.

Scheiner, S.M., Willig M.R. (2007). A general theory of ecology. Theoretical Ecology, DOI 10.007/S1 2080-007-0002.0.

Simberloff, D., Farr, J.A., Cox, J. \& Mehlman, D.W. (1992). Movement corridors: conservation bargains or poor investment? Conservation Biology 6: 493-504.

Tilman, D. (1985). The resource-ratio hypothesis of plant succession. Am. Nat. 126(6): 825852.

Turner, M.G. (1987). Landscape heterogeneity and disturbance. Springer-Verlag, New York.

Turner, M.G. (1989). Landscape ecology: the effect of pattern on process. Annu.Rev. Ecol.Syst. 20: 171-197.

Uexküll, J. von (1982). The theory of meaning. Semiotica 42(1): 25-82.

Vlasakova, B., Raabova, J., Kyncl, T., Dostal, P., Kovarova, M., Pavel, K. \& Herben, T. 2009. Ants accelerate succession from mountain grassland toward spruce forest. Journal of Vegetation Science 20: 577-587.

Wiens, J. (1994). Habitat fragmentation: island $\mathrm{v}$ landscape perspectives on bird conservation. Ibis 137: S97-S104.

Wiens, J., Milne, B. (1989). Scaling of 'landscapes' in landscape ecology, or, landscape ecology from a beetle's perspective. Landscape Ecology 3(2): 87-96

Wu, J., Hobbs, R. (2002). Key issues and research priorities in landscape ecology: an iioyncratic synthesis. Landscape Ecology 17: 355-365.

Zalasiewicz, J. (2008). Are we now living in the Anthropocene? GSA Today 18 (2): 4-8. DOI:10.1130/GSAT01802A.1. 